\title{
Effect of work function and cohesive energy of the constituent phases of Ti-50 at.\% Al cathode during arc deposition of Ti-Al-N coatings
}

Bilal Syed, Mats J . Jöessar, Peter Polcik, Szilard Kolozsvari, Greger Håkansson, Lars J ohnson, Mats Ahlgren and Magnus Odén

The self-archived postprint version of this journal article is available at Linköping University Institutional Repository (DiVA):

http:// urn.kb.se/ resolve?urn=urn:nbn:se:liu:diva-152247

N.B.: When citing this work, cite the original publication.

Syed, B., Jöessar, M. J ., Polcik, P., Kolozsvari, S., Håkansson, G., J ohnson, L., Ahlgren, M., Odén, M., (2019), Effect of work function and cohesive energy of the constituent phases of Ti-50 at.\% Al cathode during arc deposition of Ti-Al-N coatings, Surface \& Coatings Technology, 357, 393-401.

https:// doi.org/ 10.1016/j.surfcoat.2018.10.027

Original publication available at:

https:/ / doi.org/ 10.1016/j.surfcoat.2018.10.027

Copyright: Elsevier

http:// www.elsevier.com/

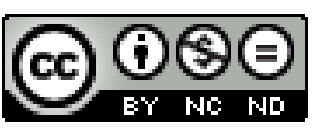




\title{
Effect of work function and cohesive energy of the constituent phases of Ti-50 at.\% Al cathode during arc deposition of Ti-Al-N coatings
}

Bilal Syed ${ }^{\mathrm{a}}$, Mats J. Jöesaar ${ }^{\mathrm{e}, \mathrm{a}}$, Peter Polcik ${ }^{\mathrm{b}}$, Szilard Kolozsvari ${ }^{\mathrm{b}}$, Greger Håkansson ${ }^{\mathrm{c}}$, Lars Johnson $^{\mathrm{d}}$, Mats Ahlgren ${ }^{\mathrm{d}}$ and Magnus Odén ${ }^{\mathrm{a}}$

\author{
Affiliations \\ a Nanostructured Materials, Department of Physics, Chemistry, and Biology (IFM), Linköping \\ University, SE-581 83 Linköping, Sweden. \\ ${ }^{b}$ PLANSEE Composite Materials GmbH, DE-86983 Lechbruck am See, Germany. \\ ${ }^{c}$ Ionbond Sweden AB, Box 1161, SE-58111 Linköping, Sweden. \\ ${ }^{d}$ Sandvik Coromant, 12680 Stockholm, Sweden \\ e SECO Tools AB, SE-737 82 Fagersta, Sweden
}

\begin{abstract}
The differences in work function (W.F.) and cohesive energy (C.E.) of the phases constituting the cathode, plays an important role in the formation of the converted layer at its nearsurface region during cathodic arc deposition. As a consequence, this also affects the deposition conditions for the coatings. In this study, we explore the effect of W.F. and C.E. of the constituent phases during arc evaporation by utilizing two kinds of customized Ti-50 at.\% $\mathrm{Al}$ cathodes with different phase compositions. Our results show that during reactive arc evaporation the disparity in W.F. and C.E. among the constituent phases of Ti-50 at.\% $\mathrm{Al}$ cathodes leads to preferential erosion of the phases with lower W.F. and C.E.. The aforementioned preferential erosion begets higher surface roughness on the Ti-50 at.\% $\mathrm{Al}$ cathode with a wider range of W.F. and C.E. disparity. It is also observed that the thermal conductivity of the Ti-50 at.\% Al cathode plays a dominant role
\end{abstract}


in the deposition rate of Ti-Al-N coating. This article also presents how the surface geometry of the cathode in the presence of arc guiding magnetic field significantly influences the microstructure of the deposited coatings.

Key words: Cathodic arc, TiAlN, work function, reactive hot isostatic pressing, coatings

\section{Introduction}

$\left(\mathrm{Ti}_{\mathrm{x}} \mathrm{Al}_{1-\mathrm{x}}\right) \mathrm{N}$ coatings are frequently used as a high performance wear and corrosion resistive coating on cutting tools due to its age hardening properties, during which the coating decomposes into coherent cubic (c)-TiN and (c)-AlN rich domains [1], activated at elevated temperatures.

Industrially, such coatings are typically deposited by PVD techniques, in particular by cathodic arc deposition [2]. Cathodic arc transforms the cathode material into a dense, highly ionized plasma [3]. The transformation of the cathode material into the plasma phase occurs explosively in a temporally and spatially confined cathode spot on the cathode surface [4]. The cathode spot appears to be stationary on the cathode surface for a time period of a few ns [5, 6]. The current density of the cathode spot is reported to be of the order of $10^{10}-10^{12} \mathrm{~A} / \mathrm{cm}^{2}[5,6]$. This high current density leads to the Joule heating of the cathode surface [7,8]. The heat modifies the surface by forming a so-called converted layer of few microns [7-9]. Several research papers have discussed the association and dynamics of the cathode spot with surface roughness $[10,11]$, surface contamination [12, 13], surface temperature [14], inclusions [15], steering magnetic field [16], and material properties like work function [17] and cohesive energy [18-20]. The significance of material properties of the cathode, e.g., work function and cohesive energy become prominent in the dynamics of the cathode spot, especially if the cathode comprises more than one phase. In 
the case of Ti-Si cathodes, it has been shown that more cathode spot events occur on the phase with low work function than the phases with comparatively higher work function during arcing [17]. Consequently, the low work function phase experiences higher erosion. Similarly, it has been shown that the cohesive energy plays an important role in ion erosion $[18,20]$. The cohesive energy of the cathode material has been shown to be critical for the vacuum arc operation as it dictates how much energy is needed for the formation of cathode spots [20, 21].

In this paper we attempt to tune the cathode material properties to influence the dynamics of the cathode spot, which in turn influences the process conditions and the coating properties. We show that by altering the work function and cohesive energy of $\mathrm{Ti}-50$ at. $\% \mathrm{Al}$ cathodes the reactive deposition conditions and the properties of the resulting Ti-Al-N coatings are influenced.

\section{Experimental methods}

Classified by microstructure, two Ti-50 at.\% Al grades were prepared. The first grade was prepared by pressing followed by forging $\mathrm{Ti}$ and $\mathrm{Al}$ powders of equal atomic percentage. The temperature during the forging was $380^{\circ} \mathrm{C}$, which is below the melting temperature of $\mathrm{Al}$ but above its recrystallization temperature. This treatment ensures that the produced grade is an elemental mixture of pure $\alpha$-Ti and $\mathrm{Al}$ (for short E.M. grade). The reported work functions of the two phases present in the E.M. grade, i.e. $\alpha-\mathrm{Ti}$ and $\mathrm{Al}$, are $4.53 \mathrm{eV}[22,23]$ and $4.08 \mathrm{eV}[23,24]$ respectively. The reported cohesive energies of $\alpha$-Ti and $\mathrm{Al}$ are $5.17 \mathrm{eV} /$ atom [25] and $3.34 \mathrm{eV} /$ atom [25, 26], respectively. The second grade was produced by reactive hot isostatic pressing (RHIP) of $\alpha$-Ti and $\mathrm{Al}$ powders of equal atomic percentage. The processing temperature during RHIP was $750{ }^{\circ} \mathrm{C}$ which is above the melting temperature of $\mathrm{Al}$ and above the recrystallization temperature of Ti. 
This temperature is sufficient to overcome the activation energy for the formation of $\varepsilon\left(\mathrm{TiAl}_{3}\right)$ through an exothermic reaction [27, 28]. The energy released by the exothermic reaction is sufficient to drive reaction further to form $\gamma(\mathrm{TiAl})$ and $\alpha_{2}\left(\mathrm{Ti}_{3} \mathrm{Al}\right)$ as final products [27-29]. The grade of material thus formed is an intermetallic mixture (for short I.M. grade) of $\gamma$ and $\alpha_{2}$. The work functions of $\alpha_{2}$ and $\gamma$, are $4.26 \mathrm{eV}$ [24] and $4.2 \mathrm{eV}$ [24] respectively. Their cohesive energies are reported to be $4.7 \mathrm{eV} /$ atom $[25,30]$ and $4.51 \mathrm{eV} /$ atom $[25,30]$ respectively. An average grain size of $50 \mu \mathrm{m}$ was selected by sieving $\alpha$-Ti and Al powders and was used as starting material for both grades. Both fabrication routes resulted in materials with oxygen contents below $3000 \mu \mathrm{g} / \mathrm{g}$ and densities greater than of $99.7 \%$ of the theoretical density. Circular cathodes, $63 \mathrm{~mm}$ in diameter, were prepared from both grades. Two different cathode surface geometries (planar and dished) were tested.

Coatings were deposited in an industrial arc deposition chamber (Metaplas MZR323) from both I.M. and E.M. grade cathodes onto mirror-like polished WC-13 wt.\% Co substrates (ISO SNUN120408, 1.2x1.2x0.5 $\mathrm{cm}^{3}$ ). Pre-deposition cleaning of the substrates was performed in two steps. The first step involved wet cleaning with alcohol in an ultrasonic bath and then dried with hot air. The second step was Ar-ion etching performed in the arc chamber prior to deposition. Four depositions were performed by dished E.M. and I.M. cathodes with different nitrogen pressure $(0.1$ $\mathrm{Pa}, 0.3 \mathrm{~Pa}, 1 \mathrm{~Pa}$, and $2 \mathrm{~Pa}$ ). Other deposition parameters include a base pressure of $2.0 \times 10^{-6} \mathrm{~Pa}$, an arc current of $75 \mathrm{~A}$, a substrate bias of $-30 \mathrm{~V}$, a constant deposition time of 10 minutes, and substrates were held stationary in front of the cathode at a distance of $15 \mathrm{~cm}$. Coatings were also deposited from planar cathodes of both grades under the same parameters as above, although only with a $\mathrm{N}_{2}$ pressure of $2 \mathrm{~Pa}$. To capture and follow the growth and evolution of the converted layer of both grades, smaller cathode pieces $\left(2 \times 1 \times 0.5 \mathrm{~cm}^{3}\right)$ of both grades were arced with the single 
trigger event as described elsewhere [19]. The pieces had a mirror-like finish achieved by sequential grinding, lapping, and polishing, where the final step removes surface oxides prior to the single trigger event.

$\mathrm{X}$-ray phase analyses of virgin cathodes, eroded cathodes and the coatings were performed in a PANalytical Empyrean diffractometer using $\mathrm{Cu}-\mathrm{K} \alpha$ radiation. For the virgin cathodes, the diffractometer was used in conventional Bragg-Brentano configuration [31]. A grazing incidence configuration [31] with a grazing angle of $1^{\circ}$ was used in the analyses of the eroded cathodes and coatings. Residual stress measurements of the coatings were performed with the same diffractometer using the $\sin ^{2} \psi$ method [32]. A Poisson's ratio of 0.25 and a Young's modulus of $386 \mathrm{GPa}[33]$ were used to determine stress.

Structural characterizations of the cathodes (virgin and eroded) and the coatings were made using a LEO 1550 Scanning electron microscope (SEM) equipped with Oxford X-Max 80 energy dispersive X-ray spectrometer (EDX) operated at an acceleration voltage of $5 \mathrm{kV}$ and a working distance of $5 \mathrm{~mm}$. The coating compositions were deduced by SEM/EDX operated with an acceleration voltage of $20 \mathrm{kV}$ and a working distance of $8.5 \mathrm{~mm}$. A standard TiAlN sample with known composition was used to calibrate the EDX data resulting in an accuracy of 5 at.\%. Crosssectional transmission electron microscopy (TEM) foils were prepared by the lift out technique [34] using a focused ion beam Zeiss 1540 EsB CrossBeam (FIB). Bright field TEM of the foils were performed using a FEI Tecnai G2 TF 20 UT FEG microscope operated at $200 \mathrm{kV}$. The transmission electron back scattered diffraction (transmission EBSD) mapping was performed with an acceleration voltage of $30 \mathrm{kV}$ on a FEI Helios Nanolab 650 (FIB) equipped with the EBSD NordlysMax 2 detector. 
The indentation hardness of the coatings was deduced by using a UMIS nanoindenter equipped with a Berkovich tip. A minimum of 40 indents were obtained from tapered polished cross sections of the samples and averaged in the evaluation. The indentation hardness was calculated from the load-displacement curves by following the method developed by Oliver and Phar [35]. Multiple steps were performed before measuring load-unload curves of the samples. These steps include calibrating the Berkovich tip's area function with a standard fused silica sample and selecting the optimum load for the coatings to avoid substrate effects[36] and so on.

The electrical conductivity of the I.M. and E.M. grade was evaluated from four-probe measurements on cut-out $2 \times 1 \times 0.5 \mathrm{~cm}^{3}$ pieces. The thermal conductivity was then extracted by the method developed by Wiedemann-Franz [37], which is based on the linear relationship between thermal and electrical conductivities. Finite element modelling of the magnetic flux density through planar and dished geometries of the cathodes was performed by using the FlexPDE 6 software. The average permeability of $\mathrm{Ti}$ and $\mathrm{Al}$ was used when modelling the magnetic flux density inside the cathode material.

Macro-particle areal densities of coatings deposited at 1 and $2 \mathrm{~Pa} \mathrm{~N}_{2}$ pressure from the different grades were determined by a box counting method. A SEM micrograph with an area of $2015 \mu \mathrm{m}^{2}$ was divided into 60 boxes and then macro-particles with a diameter larger than $1 \mu \mathrm{m}$ in each box were counted. The number of macro-particles counted from 60 boxes was then divided by the area of the micrograph. To achieve reliable macro-particle areal density, four micrographs from different locations of each coating were used and the macro-particle areal density reported is the average from the four locations. Surface roughness of both the eroded cathodes and the coatings was averaged from six roughness measurements performed at different places on each sample by the Mitutoyo Surftest SJ-210 profilometer. In order to ascertain the work function of (c) - TiAlN, 
UPS (ultra-violet photo electron spectroscopy) measurements were performed on the (c) - TiAlN coating by using Kratos Analytical Axis Ultra DLD.

\section{Results}

The dual-phase microstructures of the virgin states of E.M. and I.M. grades are distinctly different, as can be seen in Fig. 1 and Fig. 2. The E.M. grade has a microstructure with $\alpha$-Ti particles (lighter contrast) embedded in an Al matrix (darker contrast) (Fig. 1 (a)), whereas the I.M. microstructure consists of $\gamma(\mathrm{TiAl})$ and $\alpha_{2}\left(\mathrm{Ti}_{3} \mathrm{Al}\right)$ as can be seen in Fig. 2 (b). Fig. 1 (b) shows the coexistence of the equiaxed $\gamma$ and lamellar $\gamma / \alpha_{2}$ grains. A grain size of $50 \mu \mathrm{m}$ (measured by the intercept method) of both grades suggests either insignificant or no grain growth during the hot forging and RHIP. Thermal conductivity of the E.M. grade is determined to be $0.42 \mathrm{~W} \mathrm{~m}^{-1} \mathrm{~K}^{-1}$ while it is $0.16 \mathrm{~W} \mathrm{~m}^{-1} \mathrm{~K}^{-1}$ for the I.M. grade.

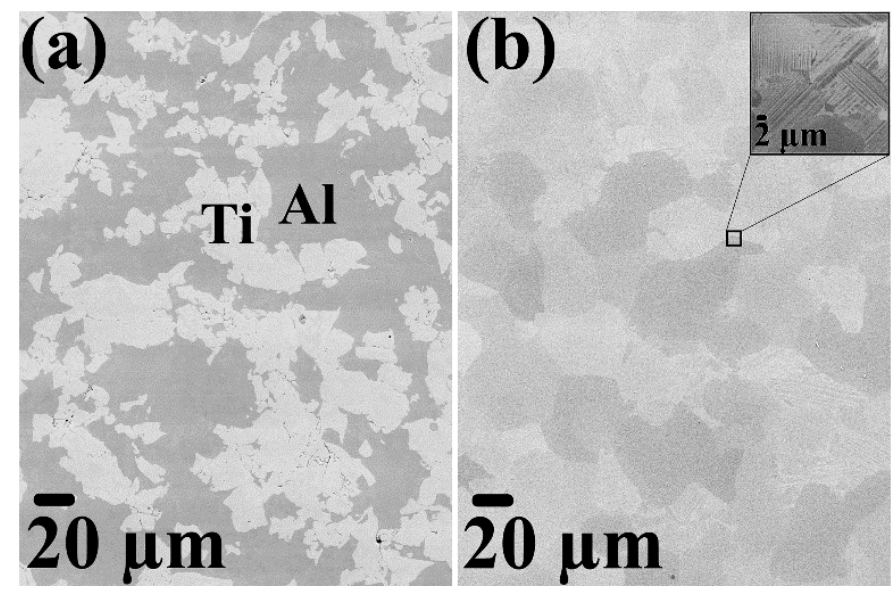

Figure 1. SEM micrographs of virgin (a) E.M. grade and (b) I.M. grade. 

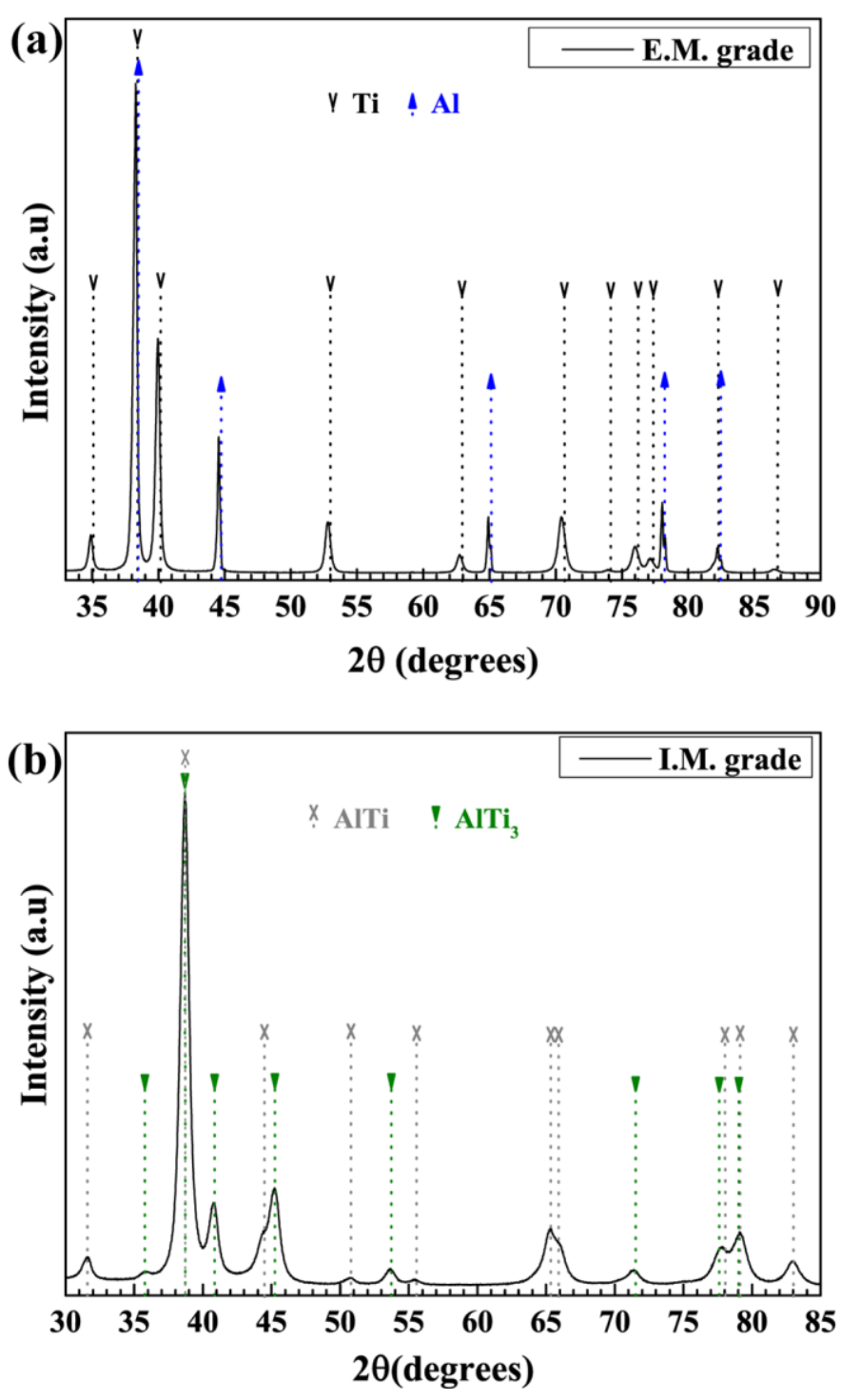

Figure 2. X-ray diffractograms of virgin (a) E.M. grade and (b) I.M. grade.

The result of a single trigger event (4.5 $\mathrm{Pa} \mathrm{N} 2$ pressure, $80 \mathrm{~A}$ arc current for $0.13 \mathrm{~s}$ ) is shown in Fig. 3 for both grades. In general, the E.M. grade (Fig 3(a)) suffers higher erosion than the I.M. grade. For the E.M. grade $\mathrm{Al}$ appears to suffer higher erosion compared to $\alpha$-Ti, and especially the sites where $\mathrm{Al}$ is sandwiched between $\alpha$-Ti grains appear to suffer heavy erosion. For the I.M. grade no such preferential erosion is observed and it appears to suffer uniform erosion of both $\alpha_{2}$ and $\gamma$ phases. 


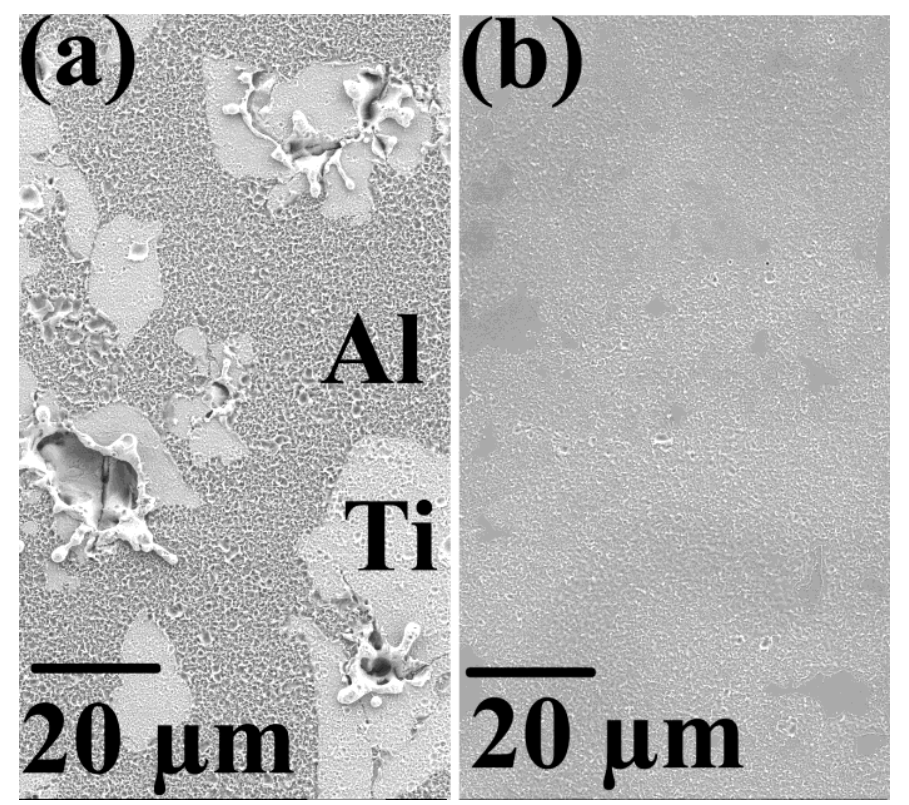

Figure 3. SEM micrograph showing the topography of (a) E.M. and (b) I.M. grades after the single trigger event (arc current $-80 \mathrm{~A}$, time $\sim 0.13 \mathrm{~s}$, and $4.5 \mathrm{~Pa} \mathrm{~N}_{2}$ ).

The topographies of the converted layers formed on the E.M. and the I.M. grade cathodes after steady state arcing in $0.1,0.3,1$ and $2 \mathrm{~Pa} \mathrm{~N}_{2}$ ambience with a constant arc current of $75 \mathrm{~A}$ for 10 minutes are shown in Fig. 4. The average crater size on the converted layers shows a decreasing trend with increasing nitrogen pressure. A similar result is observed for both grades. The as-formed converted layer on the E.M. grade cathode exhibits multiple holes (encircled in Figs. 4 (a-d)) with an average crater diameter of $9 \mu \mathrm{m}, 6 \mu \mathrm{m}, 3 \mu \mathrm{m}$ and $2 \mu \mathrm{m}$ for layers formed at $0.1,0.3,1$ and $2 \mathrm{~Pa}$ $\mathrm{N}_{2}$ pressures respectively. The average crater diameter formed on the I.M. grade and under the same operation conditions are $12 \mu \mathrm{m}, 9 \mu \mathrm{m}, 6 \mu \mathrm{m}$ and $4 \mu \mathrm{m}$ respectively.

The surface of the arced E.M. grade appears to be rougher compared to the surface of I.M. grade cathode (surface roughness values are tabulated in table 1). The bright field micrographs in Fig. 5 show that the converted layers have equiaxed grains and the grain size of the converted layers for both grades decreases with increasing $\mathrm{N}_{2}$ pressure. The converted layers formed at $0.1 \mathrm{~Pa} \mathrm{~N}_{2}$ 
pressure on the E.M. and I.M. grade comprise of equiaxed grains with an average grain size of around $200 \mathrm{~nm}$ and $300 \mathrm{~nm}$ respectively. The converted layers formed at $2 \mathrm{~Pa} \mathrm{~N}_{2}$ pressure on the E.M. and I.M. grade contain equiaxed grains with an average grain size of $10 \mathrm{~nm}$ and $25 \mathrm{~nm}$ respectively.

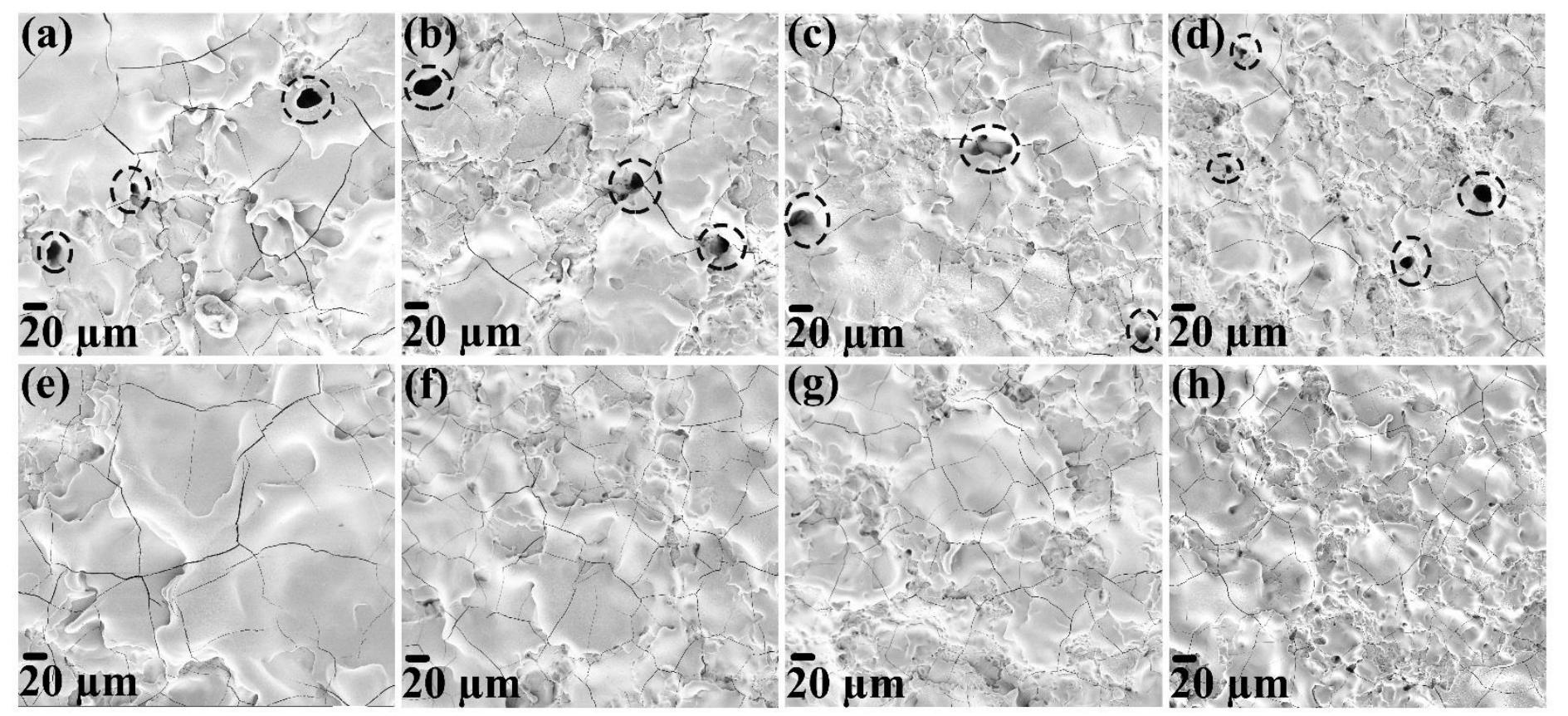

Figure 4. Topography of converted layers formed after steady state arcing on cathodes of the $((\mathbf{a})-(\mathrm{d}))$ E.M. and $((\mathrm{e})-(\mathrm{h}))$ I.M. grades in nitrogen ambience of 0.1, 0.3, 1 and 2 Pa and an arc current of $75 \mathrm{~A}$ for $10 \mathrm{~min}$, respectively. 


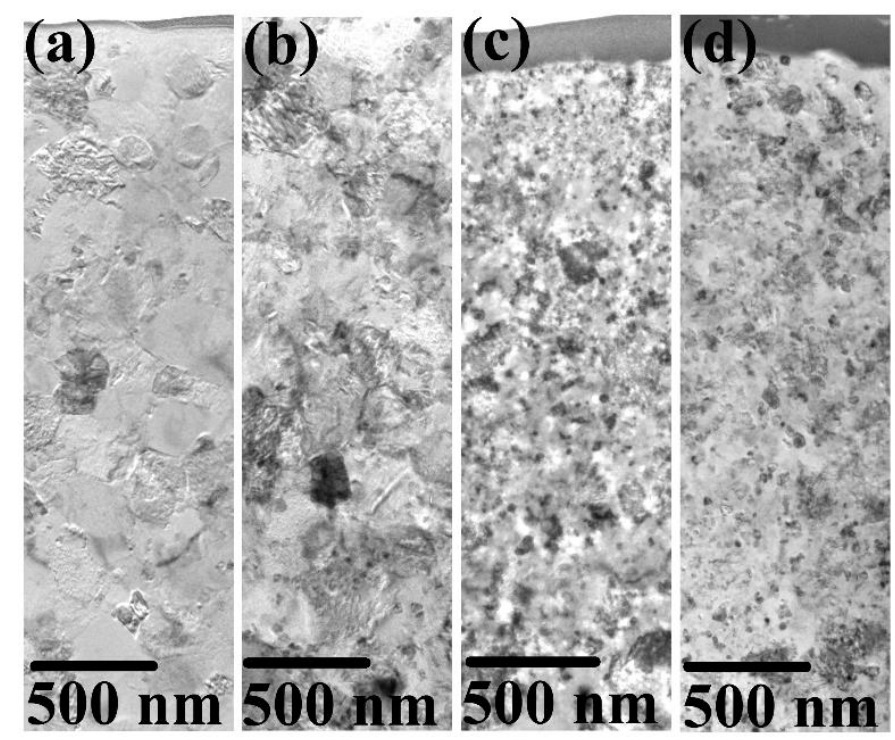

Figure 5. TEM-bright field micrographs of the cross-section of converted layers of (a) E.M. and (b) I.M. grades arced in 0.1Pa of $\mathrm{N}_{2}$ ambience and an arc current of $75 \mathrm{~A}$ for $10 \mathrm{~min}$, and (c) E.M. and (d) I.M. grades arced in $2 \mathrm{~Pa}$ of $\mathrm{N}_{2}$ ambience and an arc current of $75 \mathrm{~A}$ for 10 min.

X-ray diffractograms shown in Fig. 6 are used for the phase analysis of constituents of the converted layers. They are for the E.M. grade Ti, Al, cubic (c)-TiAlN, $\zeta\left(\mathrm{Al}_{5} \mathrm{Ti}_{2}\right), \eta\left(\mathrm{Al}_{2} \mathrm{Ti}\right)$ and $\gamma$ (AlTi), while the phases present in the converted layers on the I.M. grade are $\alpha_{2}\left(\mathrm{AlTi}_{3}\right), \gamma(\mathrm{AlTi})$, c-TiAlN, $\zeta\left(\mathrm{Al}_{5} \mathrm{Ti}_{2}\right)$, and $\eta\left(\mathrm{Al}_{2} \mathrm{Ti}\right)$. For both grades an increase in peak intensity of c-TiAlN with an increase in the $\mathrm{N}_{2}$ pressure is observed which suggests the enrichment of converted layers by the c-TiAlN. The difference between the constituents of the E.M. and I.M. grades is the presence of $\mathrm{Ti}$ and $\mathrm{Al}$ in the converted layers of the E.M. grade. 
(a)

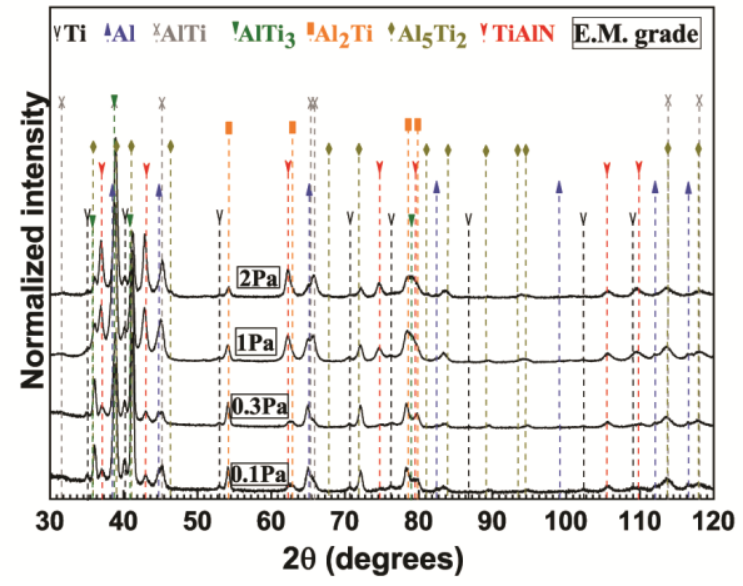

(b)

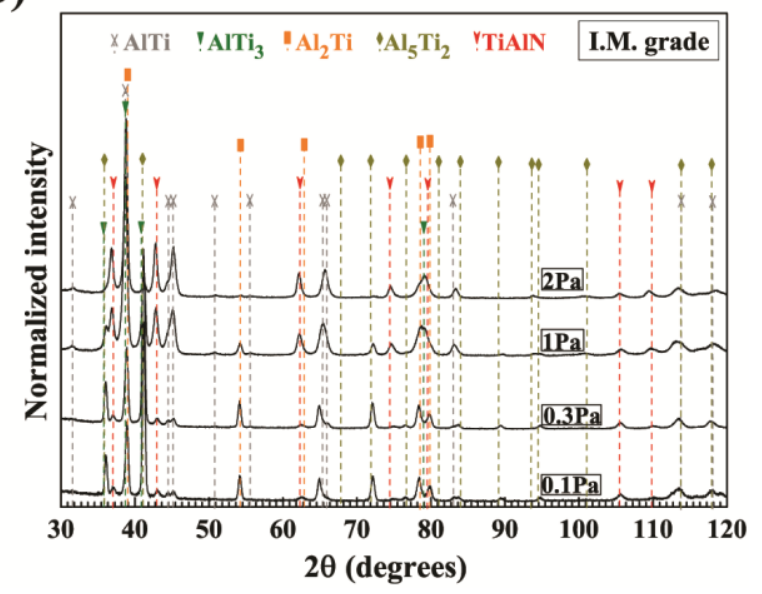

Figure 6. Converted layers of (a) E.M. and (b) I.M. grades operated at process conditions of $0.1,0.3,1$ and $2 P a$ of $N_{2}$ ambience and arc current of $75 \mathrm{~A}$ for $10 \mathrm{~min}$.

Several phases contribute to some XRD peaks, which makes the quantification of the phase fractions in the converted layers less certain. From the work function and cohesive energy perspective, all the intermetallic phases in the converted layers of I.M. grade are similar, while the constituents of the converted layers of the E.M. grade are quite different due to the presence of $\mathrm{Ti}$ and $\mathrm{Al}$. To approximate the phase fraction of $\mathrm{Ti}$ and $\mathrm{Al}$ in the converted layers of the E.M. grade transmission EBSD mapping was used. Although transmission EBSD was performed only on the converted layer formed at $2 \mathrm{~Pa} \mathrm{~N}$, similar ratios of phase fractions can be expected for the converted layers formed at other $\mathrm{N}_{2}$ pressures. The results indicate that $\alpha$-Ti accounts for $47 \%$ of the phase fraction, while $\mathrm{Al}$ accounts for approximately $16 \%$ of the phase fraction. The unresolved phase fraction stems from several reasons including grains with a diameter less than the detection limit $(20 \mu \mathrm{m})$, grain boundaries, and unresolved (c)-TiAlN. The latter is a solid solution of TiN and AlN and its crystallographic information will vary depending on the Ti/Al ratio. For this reason (c)-TiAlN was not included in the EBSD analysis. 


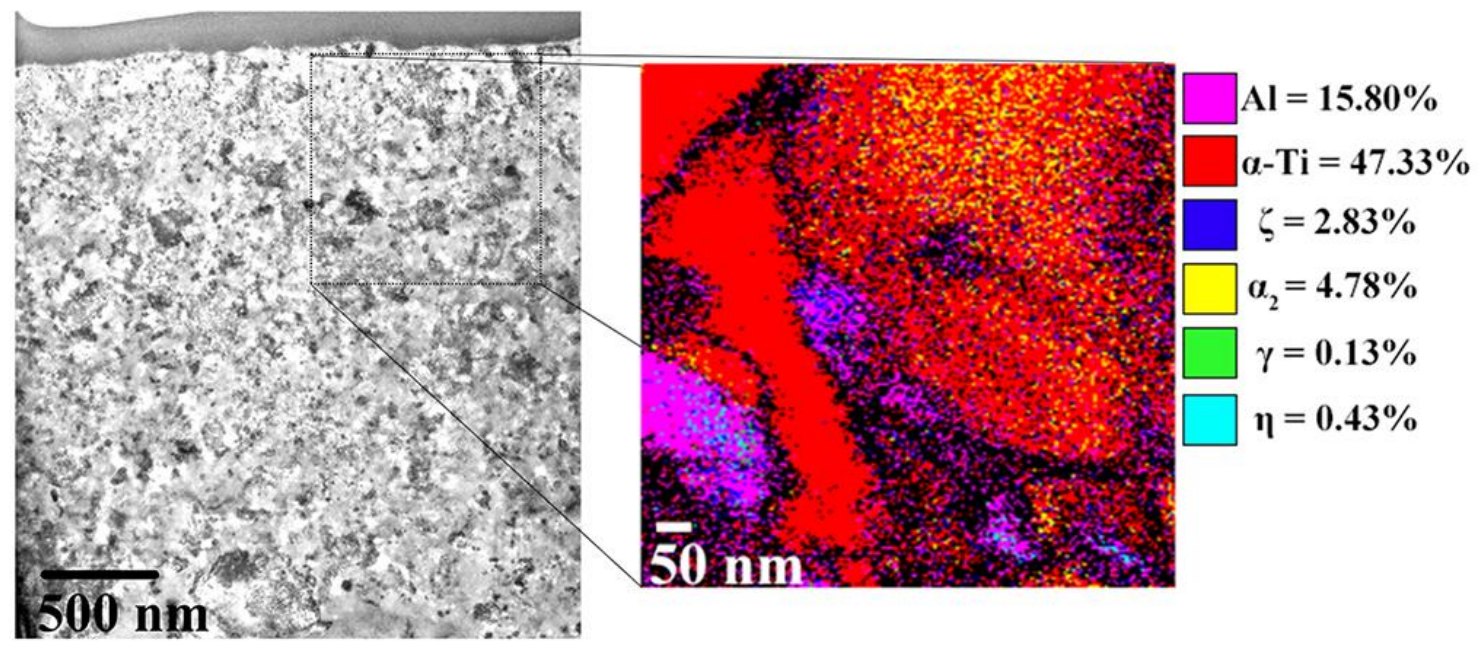

Figure 7. (left) TEM bright field micrograph of E.M. converted layer-2 Pa $\mathrm{N}_{2}$ and an arc current of 75 A for 10 min (right) transmission EBSD phase map displaying the fraction of phases found.

The magnetic field (B) of the arc guiding magnet and the electric field (E) of the cathode fall accomplish effective trapping of electrons creating an ExB drift current. This drift current has the highest current density at the regions where the vector product ExB is maximum, or in other words, where the magnetic field is parallel to the cathode surface [38]. Fig. 8 shows a 2D FEM modeling of the magnetic flux density of the arc source. The higher density of electrons at a selected region in front of the cathode creates anisotropy in the plasma density (sheath) in front of the cathode surface and anisotropy in the electric field at the cathode surface. The higher intensity of the electric field at the cathode surface where the magnetic field is parallel to the cathode surface increases the probability of cathode spot ignition at this region, which is often referred to as the acute angle rule $[23,39,40]$. In the case of a planar cathode (Fig. 8(a)) and according to the acute angle rule, the cathode spots tend to reside mostly at the edges of cathode surface which increases the probability of cathode spots to appear at surface $G$ of the cathode. In the case of a dished cathode, the acute angle rule dictates a higher ignition probability of the cathode spots at surface A 
in proximity of surface $\mathrm{C}$ (see Fig. 8(b)), while surface $\mathrm{C}$ acts as a barrier to the ignition of cathode spot at surface G.

Macro-particles are known to emit at shallow angles from the cathode surface [41]. Surface G makes shallow angles with the direction towards the substrates. For the plane cathode geometry, the probability that cathode spots form on surface $\mathrm{G}$ is high, the deposited coatings can thus be expected to be laden with macro-particles irrespective of the material grade (see Fig. 9). These coatings show inferior mechanical properties and thus will not be further discussed.

(a)
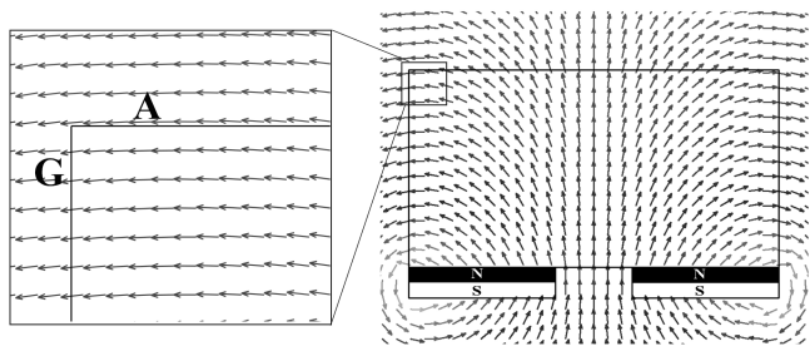

(b)

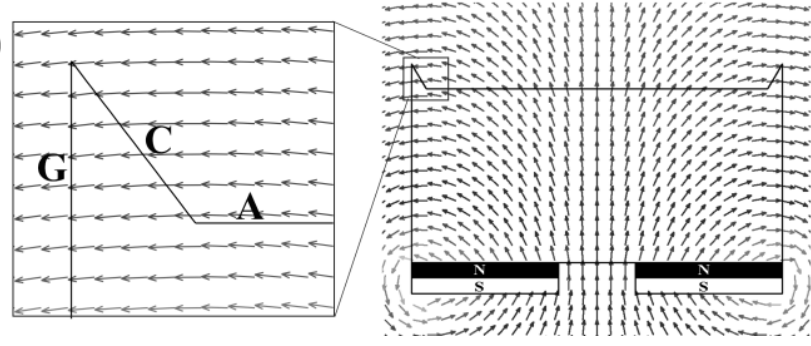

Figure 8. FEM modelling of magnetic field lines on (a) planar cathode and (b) dished cathode. The modeled magnetic field is due to the ring-shaped permanent magnet placed behind the cathodes. 


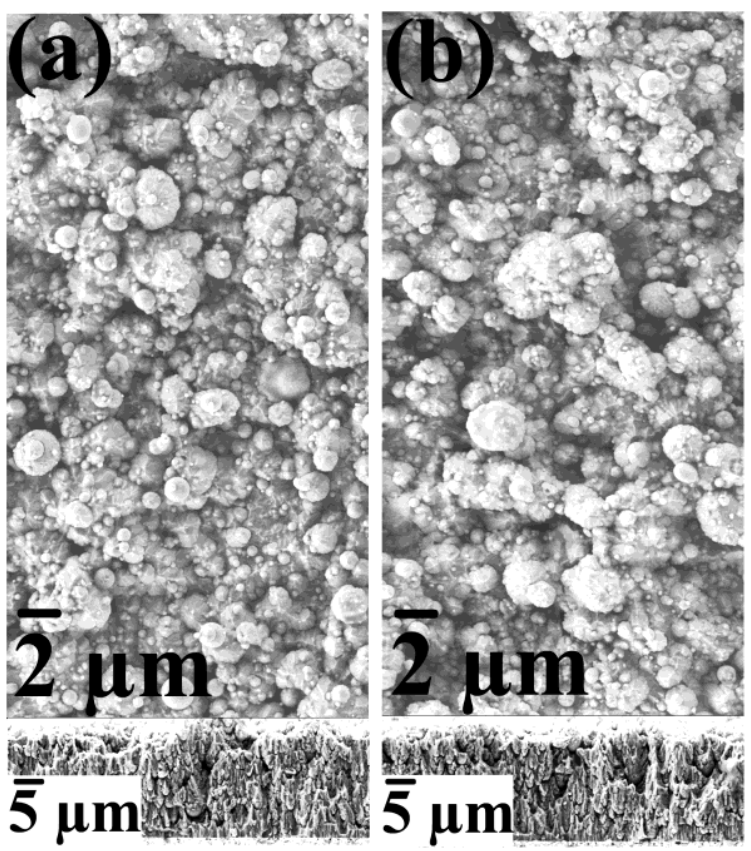

Figure 9. SEM micrograph showing the topography and cross-section of the coatings deposited at $2 \mathrm{~Pa} \mathrm{~N}_{2}$ pressure, an arc current of $75 \mathrm{~A}$ for $10 \mathrm{~min}$, a substrate bias of $-30 \mathrm{~V}$, and $15 \mathrm{~cm}$ of distance between cathode and substrate by planar cathodes of (a) E.M. and (b) I.M. grades.

The topography and fractured cross-section of the coatings deposited by the dished cathodes under $0.1,0.3,1$ and $2 \mathrm{~Pa} \mathrm{~N}_{2}$ pressure, an arc current of 75 A for 10 minutes, a substrate bias of $30 \mathrm{~V}$, and $15 \mathrm{~cm}$ of distance between cathode and substrate are shown in Fig. 9. Irrespective of the cathode grade, the coatings deposited at 0.1 and $0.3 \mathrm{~Pa} \mathrm{~N}_{2}$ pressure show large amounts of macroparticles. Coatings deposited by the I.M. grade exhibit a higher population of macro-particle compared to the coatings deposited by the E.M. grade. The areal densities of the macro-particle with diameters larger than $1 \mu \mathrm{m}$ on the coatings deposited at 1 and $2 \mathrm{~Pa} \mathrm{~N}_{2}$ pressure by the E.M. grade are 0.253 and 0.091 particles $/ \mu \mathrm{m}^{2}$, respectively. The corresponding values for coatings deposited by the I.M. grade are 0.337 and 0.135 particles $/ \mu \mathrm{m}^{2}$. As observed in the fractured crosssectional micrographs (Fig. 10), the coating thickness decreases with increase in $\mathrm{N}_{2}$ pressure. The thickness of the coatings deposited by I.M. grade is larger than the thickness of the coatings 
deposited by the E.M. grade at respective $\mathrm{N}_{2}$ pressures. The coatings reveal a columnar structure which is frequently terminated by macro-particles in the coatings deposited under 0.1 and $0.3 \mathrm{~Pa}$ $\mathrm{N}_{2}$ pressures.
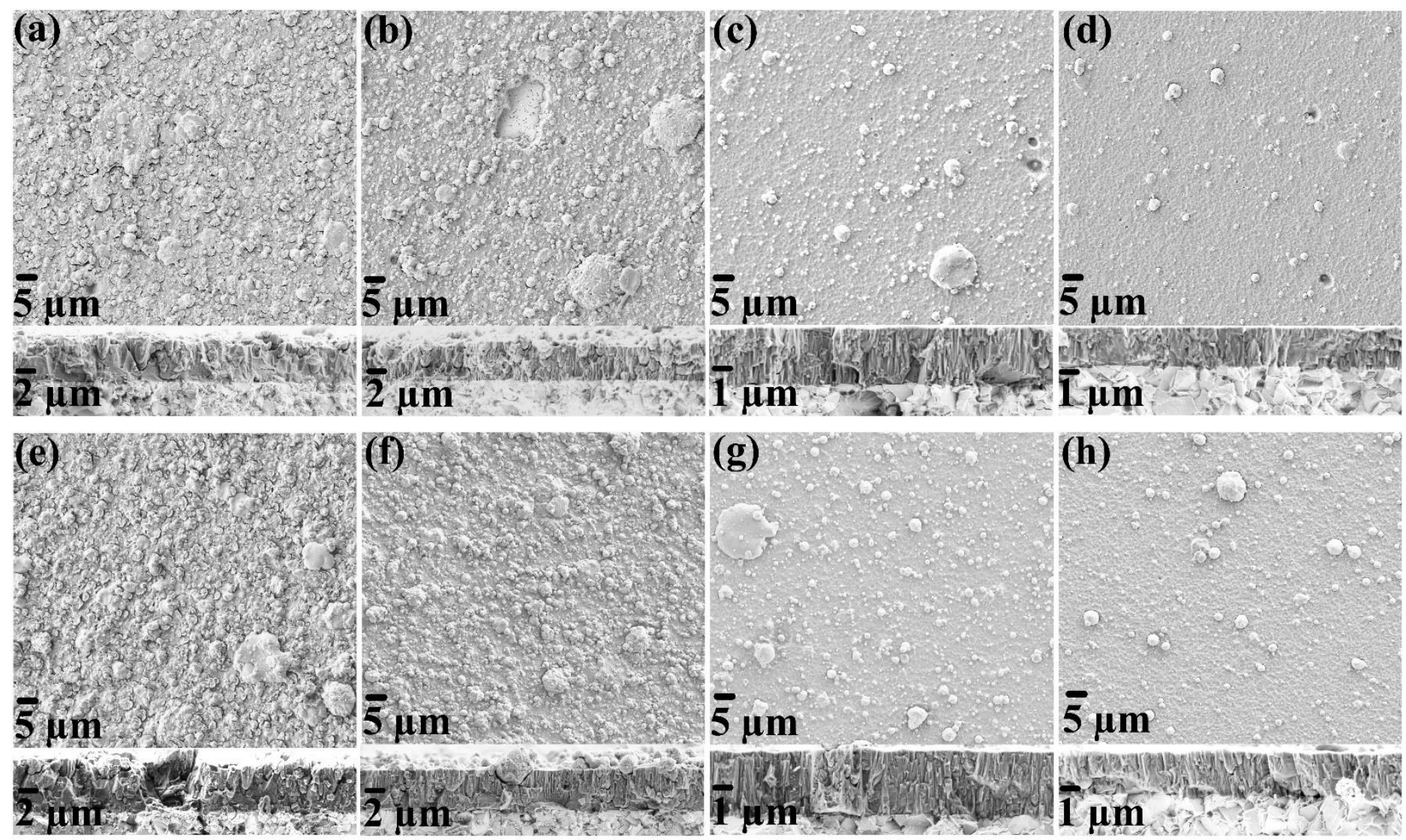

Figure 10. SEM micrograph showing the topography as well as fractured cross-section of the coatings deposited at $0.1,0.3,1$ and $2 \mathrm{~Pa} \mathrm{~N}_{2}$ pressure, an arc current of $75 \mathrm{~A}$ for $10 \mathrm{~min}$, a substrate bias of $\mathbf{- 3 0} \mathrm{V}$, and $15 \mathrm{~cm}$ of distance between cathode and substrate by (a) - (d) E.M. and (e) - (h) I.M. grades, respectively.

Fig. 11 shows $\mathrm{X}$-ray diffractograms of the coatings deposited by both grades at $0.1,0.3,1$ and $2 \mathrm{~Pa} \mathrm{~N}_{2}$ pressure, an arc current of $75 \mathrm{~A}$ for 10 minutes, a substrate bias of $-30 \mathrm{~V}$, and $15 \mathrm{~cm}$ of distance between cathode and substrate. All coatings deposited at a $\mathrm{N}_{2}$ pressure ranging from 0.1 to $1 \mathrm{~Pa}$ contain $\mathrm{Ti}$ and c-TiAlN phases. The diffraction intensities of the Ti decrease while the 
diffraction intensities of c-TiAlN increase as the $\mathrm{N}_{2}$ pressure increases. Eventually, the Ti phase vanishes at a $\mathrm{N}_{2}$ pressure of $2 \mathrm{~Pa}$. The EDX analysis of the coatings deposited by both grades at 2 $\mathrm{Pa} \mathrm{N}_{2}$ pressure, an arc current of $75 \mathrm{~A}$ for 10 minutes duration, a substrate bias of $-30 \mathrm{~V}$, and 15 $\mathrm{cm}$ of distance between cathode and substrate shows a $\operatorname{Ti}_{0.54} \mathrm{Al}_{0.46} \mathrm{~N}$ composition with a residual stress of $-2.7 \pm 0.3 \mathrm{GPa}$. The nanoindentation hardness values for the coatings deposited by both grades at $\mathrm{N}_{2}$ pressure of 1 and $2 \mathrm{~Pa}$ (arc current 75A for 10 minutes, a bias voltage of $-30 \mathrm{~V}$, and 15 cm distance between cathode and substrate) are $33 \pm 1 \mathrm{GPa}$.

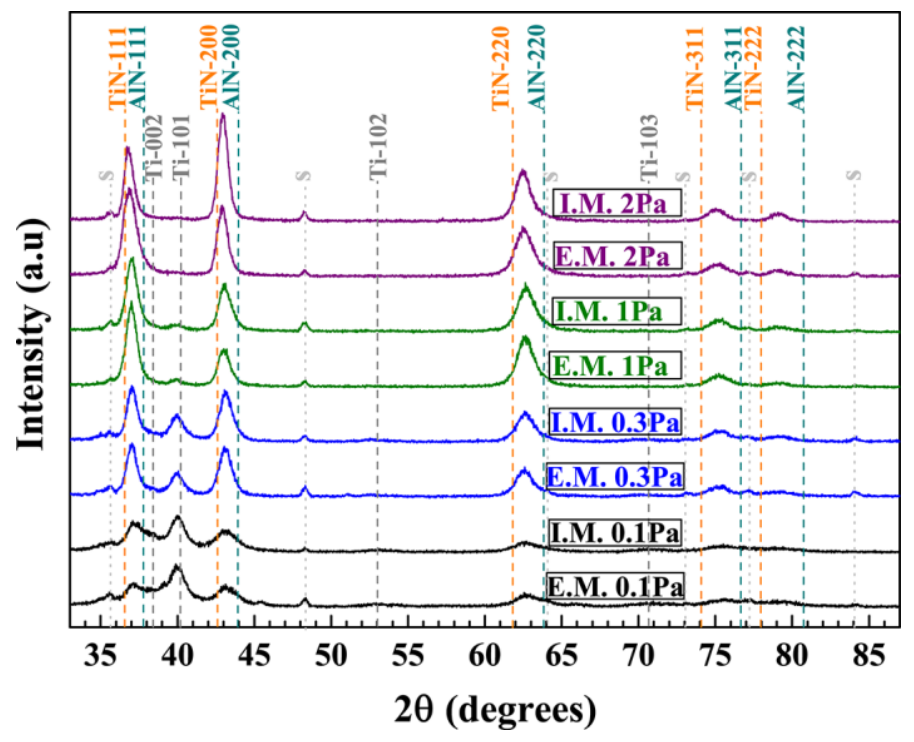

Figure 11. X-ray diffractograms of coatings deposited at $0.1,0.3,1$ and $2 \mathrm{~Pa} \mathrm{~N}_{2}$ pressure, an arc current of $75 \mathrm{~A}$ for $10 \mathrm{~min}$, a substrate bias of $-30 \mathrm{~V}$, and $15 \mathrm{~cm}$ of distance between cathode and substrate by E.M. and I.M. grades.

Table 1. Surface roughness of eroded cathodes and coatings

\begin{tabular}{lllll}
\hline \hline Category & $\mathbf{0 . 1} \mathbf{P a}$ & $\mathbf{0 . 3 ~ P a}$ & $\mathbf{1 . 0} \mathbf{P a}$ & $\mathbf{2 . 0} \mathbf{P a}$ \\
\hline E.M.- cathode roughness (Rz) & $29.62 \pm 0.81 \mu \mathrm{m}$ & $24.15 \pm 1.52 \mu \mathrm{m}$ & $22.26 \pm 1.55 \mu \mathrm{m}$ & $18.53 \pm 1.62 \mu \mathrm{m}$ \\
I.M.- cathode roughness (Rz) & $26.02 \pm 0.84 \mu \mathrm{m}$ & $22.11 \pm 1.65 \mu \mathrm{m}$ & $20.34 \pm 0.47 \mu \mathrm{m}$ & $15.69 \pm 0.71 \mu \mathrm{m}$ \\
E.M.- coating roughness (Rz) & $5.13 \pm 0.84 \mu \mathrm{m}$ & $4.18 \pm 0.25 \mu \mathrm{m}$ & $3.23 \pm 0.03 \mu \mathrm{m}$ & $1.69 \pm 0.02 \mu \mathrm{m}$ \\
I.M.- coating roughness (Rz) & $4.90 \pm 0.88 \mu \mathrm{m}$ & $4.65 \pm 0.32 \mu \mathrm{m}$ & $4.07 \pm 0.53 \mu \mathrm{m}$ & $2.57 \pm 0.13 \mu \mathrm{m}$ \\
\hline \hline
\end{tabular}


Fig. 12 shows the deposition rates of the coatings deposited at $0.1,0.3,1$ and $2 \mathrm{~Pa} \mathrm{~N}_{2}$ pressure by both grades, with an arc current of 75 A for 10 minutes, a substrate bias of $-30 \mathrm{~V}$, and $15 \mathrm{~cm}$ of distance between cathode and substrate. The rates were calculated by dividing the thickness of coatings with a constant deposition time of 10 minutes. Irrespective of the cathode grade the results show a decline in deposition rate as the $\mathrm{N}_{2}$ pressure increases. In general, the deposition rates of the I.M. grade are higher than the deposition rates of the E.M. grade for the $\mathrm{N}_{2}$ pressure range of 0.1 to $2 \mathrm{~Pa}$.

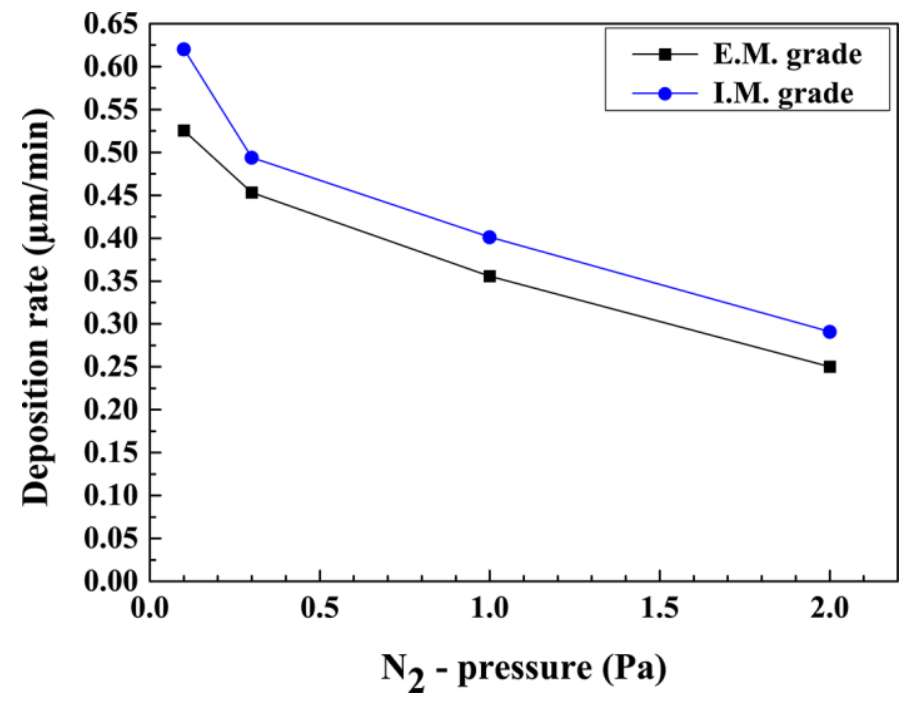

Figure 12. Deposition rates of the coatings deposited from E.M. and I.M. grade cathodes at 0.1, 0.3, 1 and 2 Pa nitrogen ambiences, an arc current of $75 \mathrm{~A}$ for $10 \mathrm{~min}$, a substrate bias of $-30 \mathrm{~V}$, and $15 \mathrm{~cm}$ of distance between cathode and substrate.

\section{Discussion}


The arcing process supplies electrons and ions to the plasma that are needed to maintain its existence. The constituent phases of the cathode surface that require the least energy for ejection of electrons and ions are the phases with the lowest work function and cohesive energy [17, 42]. During the single trigger event experiments, the cathode spot is active on the virgin material. In the case of the E.M. grade, the disparity among the virgin parent phases in terms of work functions (W.F.) and cohesive energies (C.E.) is quite high ( $\Delta$ W.F. $\sim 0.42 \mathrm{eV}, \Delta$ C.E. $\sim 1.81 \mathrm{eV}$ ) which leads to a pronounced erosion of $\mathrm{Al}$ compared to $\alpha$-Ti (see Fig. 3(a)). In the case of I.M. grade, the difference of W.F. and C.E. among the virgin phases is quite small ( $\Delta$ W.F. $\sim 0.06 \mathrm{eV}, \Delta$ C.E. $\sim 0.23$ eV)) which results in uniform erosion during the single trigger event (see Fig. 3(b)).

The steady state arcing of the E.M. grade promotes the intermixing of $\alpha$-Ti (W.F. $\sim 4.53$ eV, C.E. $5.17 \mathrm{eV} /$ atom) and $\mathrm{Al}$ (W.F. $4.08 \mathrm{eV}$, C.E. $3.34 \mathrm{eV} / \mathrm{atom})$ to form additional phases comprising of $\zeta$ (W.F. $\sim 4.16 \mathrm{eV}$ [24], C.E. $\sim 4.18 \mathrm{eV} /$ atom [25]), $\eta$ (W.F. $\sim 4.17 \mathrm{eV}$ [24], C.E. $4.24 \mathrm{eV} /$ atom [25]), $\gamma$ (W.F. 4.20 eV, C.E. 4.5eV/atom ), $\alpha_{2}$ (W.F $~ 4.26 \mathrm{eV}$, C.E. $4.7 \mathrm{eV} /$ atom), and (c)-TiAlN (W.F $\sim 4.75 \mathrm{eV}$ ). Intermixing of $\gamma$ (W.F. $\sim 4.20 \mathrm{eV}$, C.E. $\sim 4.5 \mathrm{eV} / \mathrm{atom}$ ) and $\alpha_{2}$ during the steady state arcing of the I.M. grade generates similar additional phases, which are observed in the case of E.M. grade (see Fig. 6). The transmission EBSD measurement of the converted layer of E.M. grade (see Fig 7) indicates that the parent phases $\alpha$-Ti and Al holds the majority of phase fraction. It signifies that compared to the I.M. grade a wider spectrum of work function and cohesive energies is available in the converted layers of the E.M. grade. This wider spectrum of work function and cohesive energy in the converted layers of the E.M. grade is expected to result in preferential erosion during steady state arcing. This is also seen as higher roughness values for the converted layers of this grade (see Fig. 4 and Table 1). The holes observed 
in the converted layer of the E.M. grade (see Fig. 4) are attributed to the formation of a gamma phase with a 5.3\% higher density compared to that of the Ti-Al powder [19].

Inherent to the arcing process, the cathode surface is locally heated by two main heat sources. The first is Joule heating $[8,43]$ caused by localized high current densities and the second is ion bombardment from the surrounding plasma [43]. The localized heating of the surface forms the molten pools and the joint effect of the plasma pressure and solidification of these pools causes the craters to appear on the cathode surface [43]. Compared to the E.M. grade, the I.M. grade is a poor thermal conductor, which indicates a slower residual heat removal rate, less undercooling of the molten pool, and the appearance of larger and wider craters on its surface (see Fig. 4). In addition, the rate of heat removal or the quenching rate has a direct impact on the microstructural evolution of converted layers where a slower quenching rate begets larger grain sizes upon solidification. The poor thermal conductivity of the I.M. grade is a major contributing factor in larger grain sizes of the converted layers on I.M. grade (see Fig. 5). Also, the formation of equiaxed grains rather than columnar grains in the converted layers on both grades can be understood from the fact that the plasma pressure, which is significantly higher than the atmospheric pressure [44], collaterally stirs the molten pool which disrupts directional solidification and leads to the formation of equiaxed grains.

An increase in $\mathrm{N}_{2}$ pressure during cathodic arc deposition leads to a decrease in mean free path of the ions, electrons, and neutrals in the plasma. Such a shortened mean free path results in enhanced plasma impedance. During the lifetime of a cathode spot the current density decreases as time progresses. Under high $\mathrm{N}_{2}$ pressure the decrease in current density during the later stage of cathode spot's lifetime engenders a new cathode spot to sustain the supply of electrons in the plasma. However, in the case of low $\mathrm{N}_{2}$ pressure the supply of electrons is still maintained even at 
the later stage of the cathode spot's life, which results in its prolonged lifetime. As the nitrogen pressure increases, a shorter lifetime of the cathode spots is expected, and smaller craters are formed on the converted layers of both grades (see Fig.4). An additional contributing factor to the smaller craters is the fact that the converted layers saturate with c-TiAlN as the $\mathrm{N}_{2}$ pressure rises (see Fig. 6). This c-TiAlN has a higher melting temperature than all the other phases present, which decreases the size of the molten pools and hence the size of the craters that form. The existence of smaller molten pools further leads to less macro-particle emission as shown on the deposited coatings by both grades (see Fig. 9).

The wider craters on the converted layers of I.M. grade compared to the E.M. grades (see Fig. 4(a)-(h)) are the remnant of wider molten pools that appear on the I.M. grade during arcing. Macro-particle emission is directly related to the surface temperature of the cathode [45]. The material with poor thermal conductivity is expected to have a higher surface temperature during the arcing process. The poorer thermal conductivity of the I.M. compared to the E.M. grade results in wider molten pools on it during arcing since the phases present on both grades are similar (see Fig. 6(a) and Fig. 6(b)). More macro-particles are expected to eject from wider molten pools than the smaller molten pools under plasma pressure. This is the reason why coatings deposited from the I.M. grade in general have higher macro-particle areal density and have higher surface roughness (see Fig. 9 and table 1).

The deposition rate of the coating is directly linked to the erosion rate of the cathode [46] which in turn is correlated with the cathode's surface temperature [14]. During arcing, the better thermal conductivity of the E.M. grade along with the presence of $\mathrm{Al}$ (superior thermal conductivity) in its converted layers ensures that these converted layers stay at lower temperatures in comparison to converted layers on the I.M. grade. Since similar phases are found on the 
converted layers of both grades it can be expected that these phases yield lower erosion on the E.M. grade which translates into lower deposition rates of coatings in comparison with the coatings deposited by the I.M. grade (see Fig.11). The gradual decrease in deposition rates observed from both grades by increasing $\mathrm{N}_{2}$ pressure takes place due to the combined effect of the short mean free path of plasma species and decrease in macro-particle density. The presence of the Ti phase (see Fig. 6) in the coatings deposited by both grades at $\mathrm{N}_{2}$ pressure ranging from 0.1 to $1 \mathrm{~Pa}$ suggests that this pressure range is not enough to completely transform the metal species into their respective nitrides. The atomic mass of $\mathrm{Al}$ is 1.77 times smaller than that of Ti. The absence of the $\mathrm{Al}$ phase in the coatings deposited at low $\mathrm{N}_{2}$ pressure can be attributed to the backscattering or sputtering of Al atoms from the coating's growth front.

\section{Conclusion}

Parities in the work functions and cohesive energies of the constituent phases of the Ti-50 at. $\% \mathrm{Al}$ cathodes are achieved by transforming the $\alpha$-Ti and $\mathrm{Al}$ phases to $\gamma$ and $\alpha_{2}$ phases through reactive hot isostatic pressing of Ti and Al compacts. Such changes of the cathode phases promote uniform erosion of cathodes and potentially higher deposition rates as in the case of Ti-Al-N coatings. Data suggests that the thermal conductivity of Ti-50 at.\% Al cathode is the dominant factor in macro-particle generation. It has been found that irrespective of work functions and cohesive energies of the virgin phases, the surface geometry of cathode in combination with the arc steering magnetic field plays a significant role in controlling the microstructure of the deposited Ti-Al-N coatings. 


\section{Acknowledgements}

The authors acknowledge the financial support from VINN Excelence Center in Research and Innovation on Functional Nanoscale Materials (FunMat-II, grant number 2016-05156) by the Swedish Governmental Agency for Innovation Systems. The authors would like to thank G. Greczynski for his assistance with the UPS measurements and W. Wan for his assistance with transmission EBSD measurements. 


\section{References:}

[1] A. Hörling, L. Hultman, M. Odén, J. Sjölén, and L. Karlsson, "Mechanical properties and machining performance of Ti1-xAlxN-coated cutting tools," Surface and Coatings Technology, vol. 191, no. 2-3, pp. 384-392, 2/21/2005.

[2] N. Norrby, M. P. Johansson, R. M'Saoubi, and M. Odén, "Pressure and temperature effects on the decomposition of arc evaporated Ti0.6Al0.4N coatings in continuous turning," Surface and Coatings Technology, vol. 209, no. Supplement C, pp. 203-207, 2012/09/25/ 2012.

[3] C. W. Kimblin, "Erosion and ionization in the cathode spot regions of vacuum arcs," Journal of Applied Physics, vol. 44, no. 7, pp. 3074-3081, 1973.

[4] G. A. Mesyats, "Ecton mechanism of the vacuum arc cathode spot," IEEE Transactions on Plasma Science, vol. 23, no. 6, pp. 879-883, 1995.

[5] V. F. Puchkarev and A. M. Murzakayev, "Current density and the cathode spot lifetime in a vacuum arc at threshold currents," Journal of Physics D: Applied Physics, vol. 23, no. 1, p. 26, 1990.

[6] S. Anders, A. Anders, and B. Juttner, "Brightness distribution and current density of vacuum arc cathode spots," Journal of Physics D: Applied Physics, vol. 25, no. 11, p. 1591, 1992.

[7] J. A. Rich, "Resistance Heating in the Arc Cathode Spot Zone," Journal of Applied Physics, vol. 32, no. 6, pp. 1023-1031, 1961.

[8] I. I. Beilis, "Application of vacuum arc cathode spot model to graphite cathode," IEEE Transactions on Plasma Science, vol. 27, no. 4, pp. 821-826, 1999.

[9] J. Q. Zhu et al., "Characterization of worn Ti-Si cathodes used for reactive cathodic arc evaporation," Journal of Vacuum Science \& Technology A: Vacuum, Surfaces, and Films, vol. 28, no. 2, pp. 347-353, 2010.

[10] Y. H. Fu, "The influence of cathode surface microstructure on DC vacuum arcs," Journal of Physics D: Applied Physics, vol. 22, no. 1, p. 94, 1989.

[11] R. Lakshminarayana and J. M. Richard, "Effect of surface roughness on erosion rates of pure copper coupons in pulsed vacuum arc system," Journal of Physics D: Applied Physics, vol. 40, no. 24, p. 7753, 2007.

[12] R. N. Szente, R. J. Munz, and M. G. Drouett, "Effect of the arc velocity on the cathode erosion rate in argon-nitrogen mixtures," Journal of Physics D: Applied Physics, vol. 20, no. 6, p. 754, 1987.

[13] J. Achtert et al., "Influence of Surface Contaminations on Cathode Processes of Vacuum Discharges," Beiträge aus der Plasmaphysik, vol. 17, no. 6, pp. 419-431, 1977.

[14] B. Juttner, H. Pursch, and V. A. Shilov, "The influence of surface roughness and surface temperature on arc spot movement in vacuum," Journal of Physics D: Applied Physics, vol. 17, no. 2, p. L31, 1984.

[15] J. T. Maskrey and R. A. Dugdale, "The role of inclusions and surface contamination arc initiation at low pressures," British Journal of Applied Physics, vol. 17, no. 8, p. 1025, 1966.

[16] R. L. Boxman, I. I. Beilis, E. Gidalevich, and V. N. Zhitomirsky, "Magnetic control in vacuum arc deposition: a review," IEEE Transactions on Plasma Science, vol. 33, no. 5, pp. 1618-1625, 2005.

[17] J. Q. Zhu et al., "Influence of Ti-Si cathode grain size on the cathodic arc process and resulting TiSi-N coatings," Surface and Coatings Technology, vol. 235, pp. 637-647, 11/25/ 2013.

[18] A. Anders, E. M. Oks, G. Y. Yushkov, K. P. Savkin, I. G. Brown, and A. G. Nikolaev, "Measurements of the total ion flux from vacuum arc cathode spots," IEEE Transactions on Plasma Science, vol. 33, no. 5, pp. 1532-1536, 2005.

[19] B. Syed et al., "Morphology and microstructure evolution of Ti-50 at.\% Al cathodes during cathodic arc deposition of Ti-Al-N coatings," Journal of Applied Physics, vol. 121, no. 24, p. 245309, 2017.

[20] A. Anders, E. M. Oks, and G. Y. Yushkov, "Cathodic arcs: Fractal voltage and cohesive energy rule," Applied Physics Letters, vol. 86, no. 21, p. 211503, 2005. 
[21] A. Anders, B. Yotsombat, and R. Binder, "Correlation between cathode properties, burning voltage, and plasma parameters of vacuum arcs," Journal of Applied Physics, vol. 89, no. 12, pp. 7764-7771, 2001.

[22] H. Malamud and A. D. Krumbein, "Measurement of the Effect of Chlorine Treatment on the Work Function of Titanium and Zirconium," Journal of Applied Physics, vol. 25, no. 5, pp. 591-592, 1954.

[23] A. Anders, Cathodic arcs : from fractal spots to energetic condensation (Springer series on atomic, optical, and plasma physics: 50). New York ; London : Springer, 2008., 2008.

[24] J. Chrzanowski, Y. Kravtsov, and B. Bieg, "Application of the work function to study the percentage composition of aluminum alloys," Scientific Journals of The Maritime University of Szczecin, Zeszyty Naukowe Akademii Morskiej w Szczecinie, Article vol. 110, no. 38, pp. 27-31, 2014.

[25] S. Jiang and S. Li, "Formation mechanism and prediction of new phases in binary metallic liquid/solid interface," Rare Metals, journal article vol. 30, no. 1, pp. 486-491, March 012011.

[26] M. P. Marder, Condensed Matter Physics, Second Edition. John Wiley and Sons, 2010, p. 562p.

[27] S. D. Š. V. Kevorkijan, "FABRICATION AND CHARACTERIZATION OF TiAl/Ti 3 Al-BASED INTERMETALLIC COMPOSITES (IMCS) REINFORCED WITH CERAMIC PARTICLES," (in English), AMES, vol. 15, no. 2, pp. 75-89, 20092009.

[28] F. Neves, T. Marcelo, and M. H. Carvalho, "Production of fully dense $(\alpha 2+\gamma)$ TiAl by reactive hot isostatic pressing (RHIP) of an elemental powder mixture," (in English), Key Engineering Materials, Article vol. 188, pp. 27-36, 01 / 01 / 2000.

[29] A. Kakitsuji and H. Miyamoto, "Synthesis of TiAl Intermetallic Compounds by Hip-Reaction Sintering," in Hot Isostatic Pressing - Theory and Applications: Proceedings of the Third International Conference Osaka, Japan 10-14 June 1991, M. Koizumi, Ed. Dordrecht: Springer Netherlands, 1992, pp. 295-300.

[30] R. R. Zope and Y. Mishin, "Interatomic potentials for atomistic simulations of the Ti-Al system," Physical Review B, vol. 68, no. 2, p. 024102, 07/14/ 2003.

[31] M. Birkholz, Thin film analysis by $x$-ray scattering. Weinheim : Wiley-VCH, 2006., 2006.

[32] P. Klimanek, "I. C. Noyan, J. B. Cohen. Residual stress - measurement by diffraction and interpretation. Springer Series on Materials Research and Engineering, edited by B. Ilschner and N. J. Grant. Springer-Verlag, New York-Berlin-Heidelberg-London-Paris-Tokyo 1987, 276 Seiten, 160 Bilder, 31 Tabellen, DM 138. -, ISBN 3-540-96378-2," Crystal Research and Technology, vol. 24, no. 2, pp. K37-K37, 1989.

[33] F. Tasnádi, I. A. Abrikosov, L. Rogström, J. Almer, M. P. Johansson, and M. Odén, "Significant elastic anisotropy in Ti1-xAlxN alloys," Applied Physics Letters, vol. 97, no. 23, p. 231902, 2010.

[34] M. Lekstrom, M. A. McLachlan, S. Husain, D. W. McComb, and B. A. Shollock, "Using the in situ lift-out technique to prepare TEM specimens on a single-beam FIB instrument," Journal of Physics: Conference Series, vol. 126, no. 1, p. 012028, 2008.

[35] W. C. Oliver and G. M. Pharr, "Measurement of hardness and elastic modulus by instrumented indentation: Advances in understanding and refinements to methodology," Journal of Materials Research, vol. 19, no. 1, pp. 3-20, 2004/001/001 2004.

[36] A. C. Fischer-Cripps, Nanoindentation [Elektronisk resurs]. New York, NY: Springer New York, 2011.

[37] C. Kittel and P. McEuen, Introduction to solid state physics, 8. ed. N.J. : Wiley, , 2005.

[38] A. Anders, "Discharge physics of high power impulse magnetron sputtering," Surface and Coatings Technology, vol. 205, pp. S1-S9, 2011.

[39] D. A. Karpov, "Cathodic arc sources and macroparticle filtering," Surface and Coatings Technology, vol. 96, no. 1, pp. 22-33, 1997/11/03/ 1997.

[40] P. D. Swift, "Macroparticles in films deposited by steered cathodic arc," Journal of Physics D: Applied Physics, vol. 29, no. 7, p. 2025, 1996.

[41] A. W. Baouchi and A. J. Perry, "A study of the macroparticle distribution in cathodic-arcevaporated TiN films," Surface and Coatings Technology, vol. 49, no. 1, pp. 253-257, 1991/12/10/ 1991. 
[42] A. Anders and G. Y. Yushkov, "Ion flux from vacuum arc cathode spots in the absence and presence of a magnetic field," Journal of Applied Physics, vol. 91, no. 8, pp. 4824-4832, 2002/04/15 2002.

[43] B. Juttner, "Formation time and heating mechanism of arc cathode craters in vacuum," Journal of Physics D: Applied Physics, vol. 14, no. 7, p. 1265, 1981.

[44] M. Jean-Luc, C. Sylvain, and K. Munther, "Erosion of carbon arc cathodes operating in the thermofield electron emission mode," Plasma Sources Science and Technology, vol. 16, no. 1, p. 33, 2007.

[45] R. L. Boxman and S. Goldsmith, "Macroparticle contamination in cathodic arc coatings: generation, transport and control," Surface and Coatings Technology, vol. 52, no. 1, pp. 39-50, 1992/03/15 1992.

[46] C. Bergman, "Arc plasma physical vapor deposition," presented at the SVC. Technical Conference, Philadelphia, 1985. 